\title{
The Sounds of Intent (SoI)_Proactive Musical Engagement of Children with Autism Using Percussion Instruments
}

\author{
Desiree Kaur, Aliza Alias \\ Faculty of Education, Universiti Kebangsaan Malaysia (UKM), Bangi, Malaysia \\ Email: eliza@ukm.edu.my
}

How to cite this paper: Kaur, D., \& Alias, A. (2021). The Sounds of Intent (SoI)Proactive Musical Engagement of Children with Autism Using Percussion Instruments. Creative Education, 12, 2915-2927. https://doi.org/10.4236/ce.2021.1212218

Received: December 1, 2021

Accepted: December 25, 2021

Published: December 28, 2021

Copyright (๑) 2021 by author(s) and Scientific Research Publishing Inc. This work is licensed under the Creative Commons Attribution International License (CC BY 4.0).

http://creativecommons.org/licenses/by/4.0/ (c) (i) Open Access

\begin{abstract}
A case study using adapted activities from the proactive domain of the Sounds of Intent (SoI) framework, was conducted at a private autism centre in Malaysia. Four male students with Autism aged 5 to 7 were selected to be participants in this study. Music in the form of singing nursery rhymes accompanied by percussion instruments was employed. The purpose of this study was to observe how the use of percussion instruments impacted proactive musical engagement of the participants. Five types of percussion instruments were used namely bells, egg shakers, tambourines, small drums with drumstick and the maracas; and nursery rhymes were sung in English and Malay Language. Descriptors from the SoI framework's proactive domain level 1 were used as the observation criteria. This study found that participants engaged in proactive musical engagements with the percussion instruments in their own ways. Observations found links to positive use in scaffolding and prompting techniques. The implication of this study is that the SoI framework is appropriate to be used in class with adaptations guided by recommended strategies to enhance the engagement of the children with Autism.
\end{abstract}

\section{Keywords}

Autism, Music, Zygonic Theory, Sounds of Intent, Special Education

\section{Introduction}

The World Health Organisation (WHO) and the American Psychiatric Association (APA) define autism into three broad characteristics which are qualitative impairment in social interaction; qualitative impairment in communication, as well as restricted, repetitive; and stereotyped patterns of behaviour, interests and 
active ties (Ockelford, 2013b). It is a neurological deficit which is also referred to as ASD or Autism Spectrum Disorder. The word spectrum denotes its varied manifestations in individuals. However, communication is a challenge which is typically observed from 18-month onwards, from the lack of eye contact, shorter attention spans and in some cases the lack of language abilities at par with their typical peers.

There are many types of interventions, including music. Music can be used in many forms for children with Autism; from music therapy with a qualified therapist to music education by music teachers or just the inclusion of music elements into existing intervention or classroom activities. One method of including music in the classroom has been successfully executing using the Sounds of Intent (SoI) framework. This framework has been used with positive outcomes for children with special needs in the United Kingdom (UK). It consists of various methods of evaluating musical engagement and its consistency amongst children with special needs and is available for use at the Sounds of Intent Website (Sounds of Intent, 2021).

Besides the SoI, other studies on music for children with Autism have reported positive results in the areas of social and communications skills (Mossler et al., 2017; Paul et al., 2015; Porter et al., 2017; Preis et al., 2016; Schwartzberg \& Silverman, 2014; Thompson, 2017; Vaiouli \& Ogle, 2015). These studies were conducted using various methods such as singing rather giving instructions verbally to the children (Paul et al., 2015), using background music in structured play (Preis et al., 2016), comparing the use of music strategies such as the use of precomposed songs, song-writing, and music stations (Vaiouli \& Ogle, 2015); and through music therapy (Mossler et al., 2017; Schwartzberg \& Silverman, 2014; Thompson, 2017). Regardless the methods and strategies used in these studies, common denominators amongst participants with Autism include positive outcomes in communications and social skills.

Therefore, a study was carried out at a private autism centre in Malaysia, on how the use of percussion instruments impacted the children with Autism's proactive musical engagement of SoI framework. This framework is underpinned by the Zygonic theory, and consists of 3 domains (proactive, interactive and reactive), whereby each domain has 6 levels. However, this paper only discusses the findings on proactive musical engagement at the first level (P1).

\subsection{Background of the Study}

Most interventions for children with Autism are guided by learning theories. For example, the rewarding of good behaviour advocated by behaviourism theorist Thorndike's Law of Effect places a high value on the use of rewards for good behaviours which encourages children to repeat them (Bourne, 2017). Another behaviourism theorist, Skinner calls the same practice the Reinforcement Theory. This means reinforcing good behaviour with rewards which is called positive reinforcement (Kail, 2016). The theories developed over the decades and have 
been used as a basis to develop interventions, by including the music in the intervention activities to help children with autism develop.

Another technique that is commonly used for children with Autism is prompting which is closely linked to the concepts of scaffolding (Klaus et al., 2019; Knight \& Sartini, 2015) and Zone of Proximal Development (ZPD) which were proposed by the sociocultural theorist Vygotsky (Kail, 2016). Prompting involves providing the support or guidance needed by the student when needed. This technique has been used with success for children with Autism in teaching via various methods such as time delay or simultaneously (Klaus et al., 2019; Knight \& Sartini, 2015; Neitzel \& Wolery, 2009). These techniques have also been successfully observed with positive results in SoI studies (Voyajolu \& Ockelford, 2016).

This study also took into consideration the zygonic theory since it was the basis in developing the SoI Framework. The zygonic theory approaches the study of musicology from a wholesome point of view culminating the theory of music itself and the listener's perspective (Ockelford, 2018). The features of music defined by the zygonic theory was used to develop the SoI framework which deduced that children with special needs to be engaged with music reactively, proactively and interactively (Cheng \& Welch, 2009; Ockelford, 2013a).

According to Ockelford (2013a, 2013b, 2018), the essence of any music is derived through imitation whereby one group of sounds imitates the another. Therefore, this makes music a "cognitive phenomenon" because it exists in the human mind. Additionally, music invokes emotional reactions through association, so, one does not require formal music education to recognise music's patterns of repetition. Repetition in music is necessary to maintain its structure in all domains at all levels. Music is strongly linked to other activities for social and communication skills (e.g. spoken language and dance or movements).

The SoI framework, represented by 3 distinct domains of reactive, proactive and interactive that each domain has 6 levels. The three identified domains share similarities with Ockelford's (2013b, 2018) comparison of how people engage with music and language. For each level, the research team also put together various methods of how to engage a child with music (Ockelford et al., 2005). According to Ockelford, Welch, Gore and Cheng (2011), the SoI framework was intended as a first step towards assisting teachers and therapists to properly gauge and assess their students' levels of musical development. However, a need was also identified to determine the consistency of the engagement. Hence, the SoI framework is equipped with descriptors for levels of engagement and determine its consistency (Ockelford et al., 2011; Sounds of Intent, 2021).

While the studies reported positive outcomes for participants in progressing along the domains, one gap identified was boundaries between domains. Ockelford et al. (2005) found that, while the framework could suggest equivalence in each section, it may not necessarily develop in symmetry to the framework. Despite SoI studies ongoing for over 17-years, the boundaries between the levels 
and domains remain unclear (Ockelford et al., 2005; Voyajolu \& Ockelford, 2016). Proactive musical engagement in the SoI meant that the children created sounds and music on their own (Voyajolu \& Ockelford, 2016). This study focuses on the first level P1 only which is making sounds unknowingly. The P1 level was developed to be progressive; which constitutes confusion and chaos (Ockelford et al., 2011; Vogiatzoglou et al., 2011).

\subsection{Problem Statement}

In Malaysia, research on Autism itself was more prevalent from 2000 onwards. According to a study published by the Ministry of Health Malaysia, out of 79 published research papers on autism between 2000 to 2014, 48.1\% were from the fields of medicine and education (Kaur et al., 2015). Studies in Malaysia tend to focus more intervention effectiveness (Mohd Noh et al., 2021; Yunus et al., 2020, 2021). However, only 4 studies were on the use of music for Autism published between 2010 to 2013 (Fong \& Jelas, 2010; Fong \& Lee, 2012; Ong et al., 2013; See, 2012). Similar to studies done in other countries, positive outcomes were noted in the areas of social and communication skills.

These four studies applied their own techniques and strategies for using music with the participants. Fong and Jelas (2010) mainly observed the reactions and changes in participants when exposed to music while Fong and Lee (2012) skewed their study towards academic skills such as learning abilities, reading skills and communication skills. See (2012) and Ong et al. (2013) on the other hand, focused more on interventions for behavioural management. Thus far, there is a lack of evidence in Malaysia, supporting the use of any framework with assessments and teaching tools that consider the participants' method of engaging with music. There is a need to include an element that allows for children to proactively engage with music and the consistency of engagement.

\section{Methodology}

This study was conducted using a multiple case study design (Fraenkel \& Wallen, 2009), at a single location. This method was applied due to the nature of the study involving participants with autism, requiring more individualized observations. Additionally, the Sol's studies were also conducted using a case study approach which is in line with the zygnoic theory, whereby each person responds to and interacts with music in their own way. Participants were 4 male students with Autism aged 5 to 7 years at a private autism centre and selection was based on purposive sampling (Fraenkel \& Wallen, 2009; Merriam \& Tisdell, 2016). Ethical considerations were also met by getting written consent from the participants' parents prior to conducting the study.

Firstly, observations were conducted by the researchers followed by adapting SoI activities within the proactive domain. According to Kaur et al. (2019), adapting activities was necessary due to cultural and language of communication differences between the UK and Malaysia. Adapted activities were validated by ex- 
perienced local practitioners in the fields of music therapy and special education. Following the validations, a pilot study was conducted to test the feasibility of activities. Upon completion of the pilot, the activities were carried out with the participants for a duration of 6-weeks, 3 times per week, (total 18 sessions) for 30 minutes each session.

The activities were singing of nursery rhymes (a mix of English and Malay Language songs) by teachers during the designated Circle Time, an activity which was already part of the students' day at school. The additional activity during circle time was the use of 5 types of percussion instruments, namely bells, egg shakers, tambourines, small drums with drumstick and the maracas. The researcher took on the role of complete observer (Fraenkel \& Wallen, 2009; Merriam \& Tisdell, 2016) during circle time using descriptors available at the SoI Website for the proactive domain's level of engagement and consistency. Each session was video recorded and observation notes were taken too. The participants communication book, was used as an artifact (Merriam \& Tisdell, 2016), when analysing the findings. The activities were conducted in a group, with a teacher was leading the singing of nursery rhymes while five other teachers were also involved in the activity to manage other students in the circle time session.

\section{Findings}

Prior to conducting this study, written permission was obtained from the private autism centre to conduct an observation to identify potential participants for this study. Subsequently, observations of existing circle time sessions were conducted. Upon identifying potential participants, written permission was obtained for participants" parents were obtained. Circle time was typically conducted by teachers singing nursery. The activity introduced was the percussion instrument, for participants to use or play with whilst the nursery rhymes were sung in English and Malay Language.

Observations on each participant are reported individually. In a qualitative study, part of data mining includes documents and artifacts that could help support the observations made and collected data. This information is considered as personal documents when mining for data from documents and artifacts (Merriam \& Tisdell, 2016). The participants' communication books fulfil this criterion and was part of the triangulation of information used to analyse the outcomes of the study. Four participants, namely, S1, S2, S3 and S4 recorded full attendance in all activities conducted at P1 level. Descriptor of P1 observed sounds made knowingly or unknowingly by the participants. The sounds observed were either made with or without co-active movements such as body movements and use of percussion instruments in any form.

\subsection{Proactive Musical Engagement for $S 1$ at $P 1$}

The following graph in Figure 1 depicts the levels of proactive musical engagement for Student 1 (S1) at P1 over 6 sessions. When the circle time activity with 


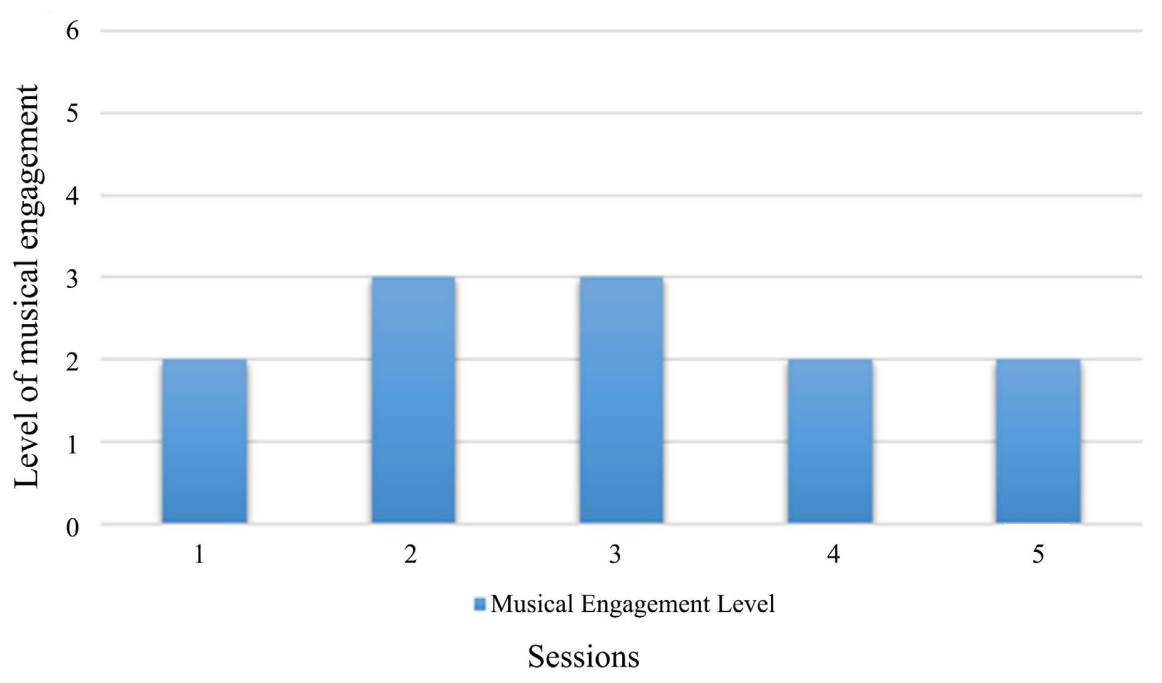

Figure 1. Proactive musical engagement level for student 1 (S1) at P1.

percussions instruments first commenced, S1 did not show any interest at all and refused to hold any of the percussion instruments and was rather disengaged from the activity. So, the teacher introduced the egg shakers and prompted $\mathrm{S} 1$ to shake them.

S1's progress at P1 showed an increased level of engagement which dropped in the last 3 sessions, for no obvious reason. His levels of engagement at P1 started low at 2 and increased to 3 for two sessions and returned to 2 for the last 3 sessions of P1. During the first exposure to percussion instruments, S1 was given the bells was prompted to ring the bells from time to time when songs were sung. During the subsequent sessions, S1 was given the egg shakers. Although S1 was disengaged from the activity, he held the eggs and rubbed them to his face, as if familiarising himself with the instrument. Once introduced to the egg shaker, S1 seemed to instinctively choose them from the box of instruments. Despite a disinterest in the activity, S1 was getting familiarised with the egg shakers.

At the 6th session at P1, S1 chose the bells instead and began to ring them. Later, S1 took one of the egg shakers and played the bells together with eggs shakers as if they were action figures. This was how S1 demonstrated proactive musical engagement with the percussion instruments. As S1 played with them, it made sounds which he seemed to enjoy. According to his teacher, S1 took a special liking to objects that replicated sounds like the egg shakers and the maracas. After exposure to percussion instruments during circle time, S1 would look for object which makes similar sounds during lesson time. So, the teacher used this opportunity to use these objects as a reward. This approach motivated S1 to be more attentive in class. Additionally, the teacher noted that $\mathrm{S} 1$ was more excited to go for the circle time activity once the percussion instruments were introduced into the activity. Additionally, notes in S1's communication book indicated good behaviour for the duration the circle time and S1's liking for items that resembled the sounds of the egg shakers and maracas in other class activity. 


\subsection{Proactive Musical Engagement for $\mathrm{S} 2$ at $\mathrm{P} 1$}

The following graph in Figure 2 shows proactive musical engagement for Student 2 (S2) at P1 over 6 sessions. S2 progressed along P1 with fluctuating levels. S2 enjoyed playing all the percussion instruments and did not show an inclination to a particular one. S2 would constantly make sounds during the singing activity with body movements and dancing.

S2 showed high levels of participation in the activity by playing with the percussion instruments and also vocalising sounds such as "eeee", "oooo" and "aaaa" in the same melody and rhythm as the songs being sung. There was also a lot of body movements, jumping up and down as well as dancing. S2 displayed proactive musical engagement with the percussion instruments at $\mathrm{P} 1$ in many ways. S2 would experiment various ways of making sounds with the percussion instruments and always in a regular beat and motion. For example, S2 would beat the tambourine with his hand, and then hit it against his head and then against his thigh in a constant rhythm. S2 even put the drum against his ear and used his hand to beat it, as if to see the difference in the sound compared to beating it with the drumstick.

\subsection{Proactive Musical Engagement for $\mathrm{S} 3$ at $\mathrm{P} 1$}

The following graph in Figure 3 depicts proactive musical engagement for Student 3 (S3) at P1 over 6 sessions. S3 did not show a preference in any percussion instrument. There were instances where S3 participated rather actively, and even vocalised sounds when the nursery rhymes were sung. However, S3 would then regress rather quickly and become disengaged from the activity.

S3's level of engagement at P1 remained in the lower range. At the first session, S3 played the bells rather excitedly but quickly lost interest and became disengaged from the activity. This behaviour progressed at every session at P1. With some prompting by his teacher, S3 would engage a little more but very quickly become disengaged and sit down quietly. While S3 was less engaged in

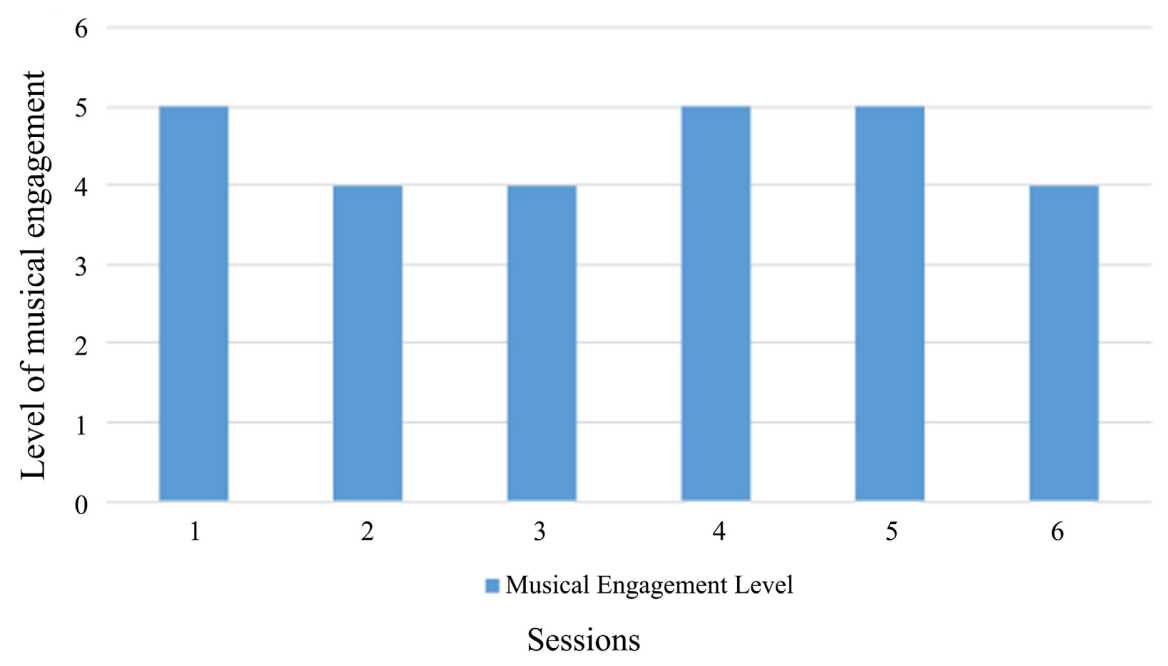

Figure 2. Proactive musical engagement level for student 2 (S2) at P1. 


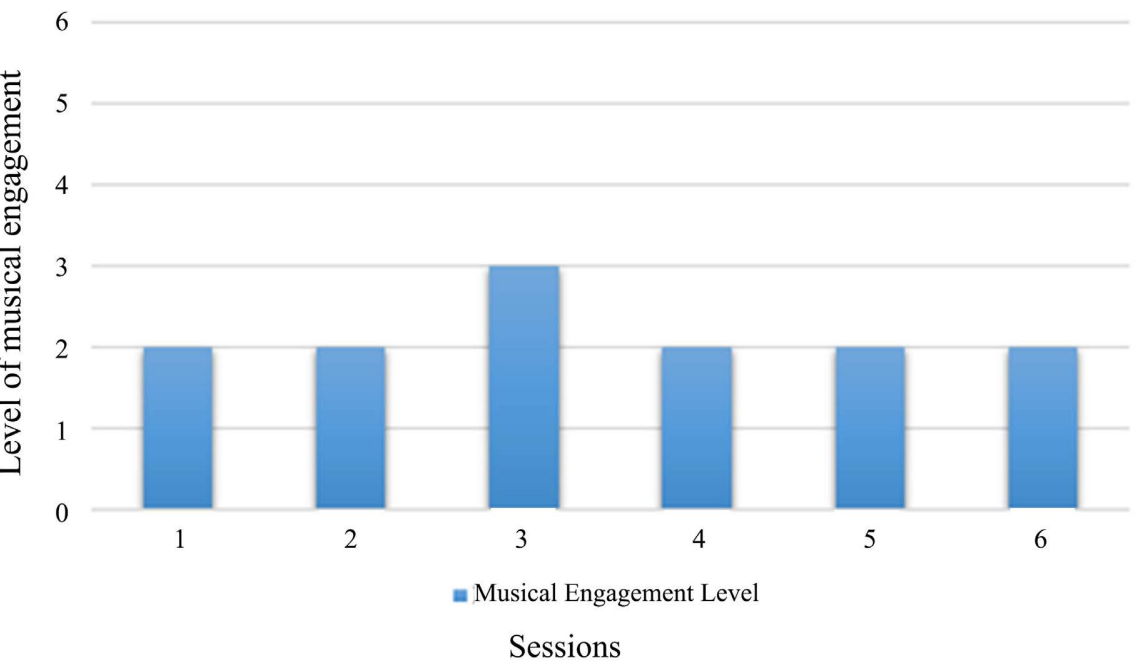

Figure 3. Proactive musical engagement level for student 3 (S3) at P1.

the circle time activity, he did display proactive musical engagement with the percussion instruments at P1. S3 rang the bells intermittently with some prompting as he sat down watching the activity, played the tambourine, and beat the drums with the drumstick after the teacher prompted him to do so. S3's use of percussion instruments required some prompting at $\mathrm{P} 1$.

\subsection{Proactive Musical Engagement for $\mathrm{S} 4$ at $\mathrm{P} 1$}

The following graph in Figure 4 depicts proactive musical engagement over 6 sessions for Student S4 at P1. S4 started off with high levels of engagement, showing a keen interest in playing the drum with drumstick and with his hand. S4 would get extremely excited, jumping up and down and trying to get the researcher's attention every time she arrived with the box of percussion instruments. S4 would try his best to get the percussion instruments out of the box before the activity commenced. S4 seemed to like the drums very much but also played other instruments such as the bells, maracas and tambourine.

At P1, S4 recorded rather high levels of engagement at 5 and one time at 6 . S4 displayed proactive musical engagement with the percussion instruments at P1 in a few ways. During circle time, there were instances where S4 beat the drum with drumstick and also chose different instruments such as the maracas and the tambourine. S4 would participate actively in the circle time activity, jumping up and down as well as clapping.

According to his teacher, $\mathrm{S} 4$ was extremely excited to participate in the circle time activity once the percussion instruments were introduced to the activity. S4 enjoyed the sounds made and making the sounds himself. The teacher also noted S4's sensitivity to the sound of bells whereby he would close his ears every time bells were rung close to him. The teacher did not observe any other changes outside of the circle time activity. S4's excitement using the percussion instruments were also noted down in his communications book. Overall notes from 


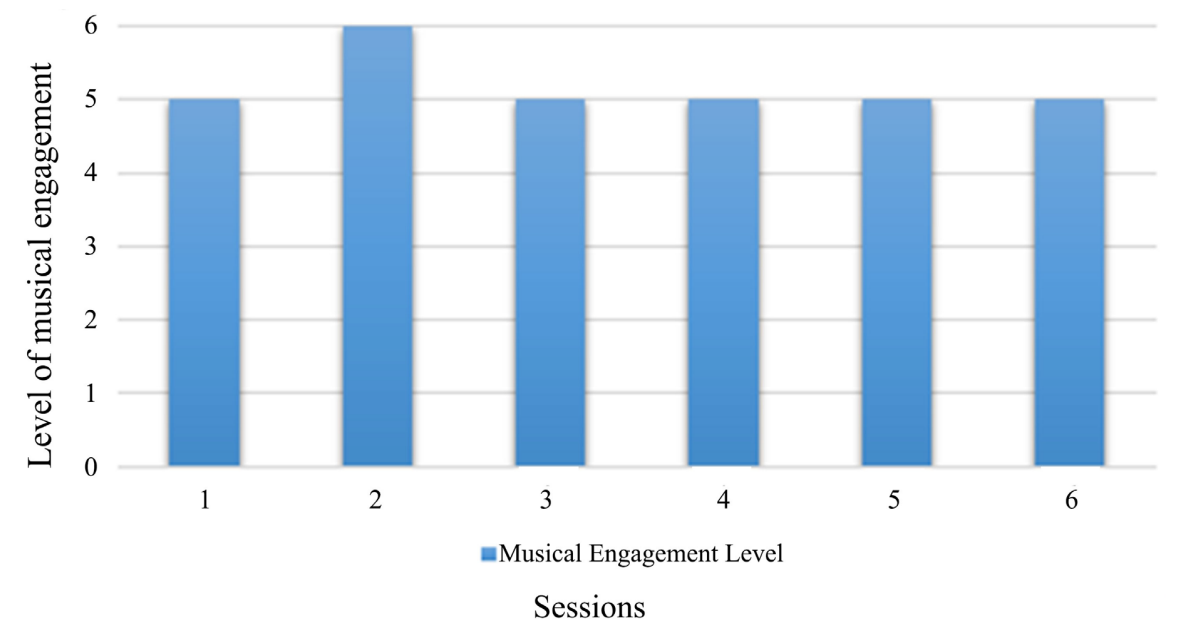

Figure 4. Proactive musical engagement level for student 4 (S4) at P1.

the teacher, indicated that $\mathrm{S} 4$ took instructions well and did not display any behavioural issues during the activities.

\section{Discussion}

All participants demonstrated proactive musical engagement with percussion instrument differently. According to Ockelford (2013b, 2018), children with special needs respond to music reactively, proactively or interactively with the possibility of any of these three overlapping. There are various methods of observing levels of proactive musical engagement. The findings of this study support the findings from observation done by Voyajolu and Ocklerford (2016) which showed the positive impact of adult support for children with special needs in the SoI framework's implementation. This is closely linked to Vygotsky's ZPD whereby prompting is one of the techniques used to create a supportive environment. Prompting worked well for most participants because the students became more familiar with making sounds with the percussion instruments after some encouragement from the teachers.

Prompting and scaffolding are important techniques in teaching practise which stems from the theory. These techniques have been used effectively in teaching children with Autism such in the form of time delay, or providing support when required (Klaus et al., 2019; Knight \& Sartini, 2015; Neitzel \& Wolery, 2009). Furthermore, other studies using music for children with Autism also included prompting and scaffolding in the teaching practice with success. While research done by Paul et al. (2015), found that singing instructions to participants with Autism was used as a communicative scaffold whereas Voyajolu and Ockelford (2016) reported a strong link between scaffolding and attaining higher levels of musical engagement.

Reinforcement theory as well as trial and error techniques are also important in teaching practice. It has been used successfully in previous studies such as by Preis et al. (2016) to find out if types of background music in a structured play 
increases engagement and number of utterances amongst children with Autism. However, negative reinforcement by preventing students from doing something they enjoy which is not overtly disruptive or a danger, should be highly discouraged. Positive reinforcement can be more successful which also supports Voyajolu and Ockelford's (2016) link to ZPD on adult support during the activities.

The zygonic theory's links to emotions (2012, 2013a, 2013b, 2018) was also observed as the participants enjoyed dancing around or jumping up and down. Nursery rhymes are typically fast tempo with connotations of happiness (Gabrielsson \& Lindstrom, 2001). Moods are also influenced by types of music (Liu et al., 2018). The students enjoyed dancing around to the nursery rhymes and they were typically smiling when doing this. This connotes happiness and enjoyment during the activities. While the zygonic theory is mainly studied by music psychologist, in terms of teaching practice, it can be used in a special education classroom by teachers who do not have musical background. The choice of songs, nursery rhymes could be used to teach emotions by the various connotations in the tempo and tune of the songs.

\section{Conclusion}

As a conclusion, using percussion instruments in the classroom enhance the proactive musical engagement of children with Autism. The SoI Framework provides a guideline for the teachers to use any musical instrument that is appropriate in conducting activities for special needs children in a classroom. Strategies proposed at the SoI Website can be adapted to suit local language and teaching practices and the activities suggested can be simplified and easily conducted by teachers who do not have any musical training. Nevertheless, future studies using the SoI should also consider external factors that may impact the children's behavior during the activities.

\section{Acknowledgements}

This work was supported by a research from Faculty of Education, Universiti Kebangsaan Malaysia (FPEND GG-2019-029).

\section{Conflicts of Interest}

The authors declare no conflicts of interest regarding the publication of this paper.

\section{References}

Bourne, P. E. (2017). Behaviourism and Learning: How Is Education Influenced by Thorndike's Thinking? International Journal of HR \& Organisational Management Insights \& Transformations, 2 .

Cheng, E., \& Welch, G. (2009). Researching and Developing Music Provision in Special Education in England for Children and Your People with Complex Needs. Australian Journal of Music Education, 2, 27-48.

Fong, C. E., \& Jelas, Z. M. (2010). Music Education for Children with Autism in Malaysia. 
Procedia-Social and Behavioral Sciences, 9, 70-75. https://doi.org/10.1016/j.sbspro.2010.12.117

Fong, C. E., \& Lee, C. S. (2012). Communication Responses of an Indian Student with Autism to Music Education. Procedia-Social and Behavioral Sciences, 65, 808-814. https://doi.org/10.1016/j.sbspro.2012.11.203

Fraenkel, J. R., \& Wallen, N. E. (2009). How to Design and Evaluate Research in Education (7th ed.). McGraw Hill.

Gabrielsson, A., \& Lindström, E. (2001). The Influence of Musical Structure on Emotional Expression. In P. N. Juslin, \& J. A. Sloboda (Eds.), Series in Affective Science. Music and Emotion: Theory and Research (pp. 223-248). UK: Oxford University Press.

Kail, R. V. (2016). Children and Their Development (7th ed.). Pearson Education Limited.

Kaur, D., Alias, A., \& Mohamad, M. (2019). The Sounds of Intent Framework for Autism Intervention: A Conceptual Paper. Creative Education, 10, 1953-1964.

https://doi.org/10.4236/ce.2019.108141

Kaur, J., Engkasan, J. P., Sivanesom, R. S., Bahar, N., Toran, H., Mat Noor, M. M., \& Kamarudin, K. N. (2015). Technical Report Autism Spectrum Disorder Research in Malaysia. Ministry of Health Malaysia.

Klaus, S., Hixson, M. D., Drevon, D. D., \& Nutkins, C. (2019). A Comparison of Prompting Methods to Teach Sight Words to Students with Autism Spectrum Disorder. Behavioral Interventions, 34, 352-365. https://doi.org/10.1002/bin.1667

Knight, V. F., \& Sartini, E. (2015). A Comprehensive Literature Review of Omprehension Strategies in Core Content Areas for Students with Autism Spectrum Disorder. Journal of Autism Development Disorder, 45, 1213-1229.

https://doi.org/10.1007/s10803-014-2280-x

Liu, Y., Liu, G., Wei, D., Li, Q., Yuan, G., Wu, S., Wang, G., \& Zhao, X. (2018). Effects of Musical Tempo on Musicians' and Non-Musicians' Emotional Experience When Listening to Music. Frontiers in Psychology, 9, 2118.

https://doi.org/10.3389/fpsyg.2018.02118

Merriam, S. B., \& Tisdell, E. J. (2016). Qualitative Research. A Guide to Design and Implementation (4th ed.). Jossey-Bass.

Mohd Noh, N. A. S. M., Kamaralzaman, S., Masuri, M. G., Mariappan, V., \& Toran, H. (2021). Satisfaction of Early Intervention Programme among Parents of Children with Autism Spectrum Disorder (ASD): A Pilot Study in Malaysia. International Journal of Academic Research in Progressive Education and Development, 10, 931-947. https://doi.org/10.6007/IJARPED/v10-i2/10247

Mossler, K., Gold, C., Aßmus, J., Schumacher, K., Calvet, C., Reimer, S., Iversen, G., \& Schmid, W. (2017). The Therapeutic Relationship as Predictor of Change in Music Therapy with Young Children with Autism Spectrum Disorder. Journal of Autism and Developmental Disorders, 49, 2795-2809. https://doi.org/10.1007/s10803-017-3306-y

Neitzel, J., \& Wolery, M. (2009). Steps for Implementation: Time Delay. The National Professional Development Center on Autism Spectrum Disorders, Frank Porter Graham Child Development Institute, The University of North Carolina.

Ockelford, A. (2013a). Applied Musicology. Using Zygonic Theory to Inform Music Education, Therapy, and Psychology Research. Oxford University Press. https://doi.org/10.1093/acprof:oso/9780199607631.001.0001

Ockelford, A. (2013b). Music, Language and Autism. Exceptional Strategies for Exceptional Minds. Jessica Kingsley Publishers. 
Ockelford, A. (2018). Comparing Notes. How We Make Sense of Music. Profile Books Limited.

Ockelford, A., Welch, G., Gore, L. J., \& Cheng, E. (2011). Sounds of Intent, Phase 2: Gauging the Music Development of Children with Complex Needs. European Journal of Special Needs, 26, 177-199. https://doi.org/10.1080/08856257.2011.563606

Ockelford, A., Welch, G., Zimmermann, S., \& Himonides, E. (2005). "Sounds of Intent": Mapping, Assessing and Promoting the Musical Development of Children with Profound and Multiple Learning Difficulties. International Congress Series, 1282, 898-902. https://doi.org/10.1016/j.ics.2005.04.007

Ong, J. H. L., Dani, N. A., \& Johari, A. Z. (2013). Auditory Stimulus for Children with High Functioning Autism: Towards Reducing Developmental Disorders and Inattentive. Australian Journal of Basic \& Applied Sciences, 7, 676-682.

Paul, A., Sharda, M., Menon, S., Arora, I., Kansal, N., Arora, K., \& Singh, N. C. (2015). The Effect of Sung Speech on Socio-Communicative Responsiveness in Children with Autism Spectrum Disorders. Frontiers in Human Neuroscience, 9, 555. https://doi.org/10.3389/fnhum.2015.00555

Porter, S., McConnell, T., McLaughlin, K., Lynn, F., Cardwell, C., Braiden, \& Holmes, V. (2017). Music Therapy for Children and Adolescents with Behavioural and Emotional Problems: A Randomised Controlled Trial. Journal of Child Psychology and Psychiatry and Allied Disciplines, 58, 586-594. https://doi.org/10.1111/jcpp.12656

Preis, J., Amon, R., Silbert-Robinette, D., \& Rozegar, A. (2016). Does Music Matter? The Effects of Background Music on Verbal Expression and Engagement in Children with Autism Spectrum Disorders. Music Therapy Perspectives, 34, 106-115. https://doi.org/10.1093/mtp/miu044

Schwartzberg, E. T., \& Silverman, M. J. (2014). Music Therapy song Repertoire for Children with Autism Spectrum Disorder: A Descriptive Analysis by Treatment Areas, Song Types, and Presentation Styles. Arts in Psychotherapy, 41, 240-249. https://doi.org/10.1016/j.aip.2014.03.007

See, C. M. (2012). The Use of Music and Movement Therapy to Modify Behaviour of Children with Autism. Pertanika Journals of Social Sciences and Humanities, 20, 1103 1116.

Sounds of Intent (2021). Sounds of Intent. http://soundsofintent.org/about-soi

Thompson, G. A. (2017). Long-Term Perspectives of Family Quality of Life Following Music Therapy with Young Children on the Autism Spectrum: A Phenomenological Study. Journal of Music Therapy, 54, 432-459. https://doi.org/10.1093/jmt/thx013

Vaiouli, P., \& Ogle, L. (2015). Music Strategies to Promote Engagement and Academic Growth of Young Children with ASD in the Inclusive Classroom. Young Exceptional Children, 18, 19-28. https://doi.org/10.1177/1096250614523968

Vogiatzoglou, A., Ockelford, A., Welch, G., \& Himonides, E. (2011). Sounds of Intent: Interactive Software to Assess the Development of Children and Young People with Complex Needs. Music \& Medicine, 3, 189-195. https://doi.org/10.1177/1943862111403628

Voyajolu, A., \& Ockelford, A. (2016). Sounds of Intent in the Early Years: A Proposed Frame Work of Young Children's Musical Development. Research Studies in Music Education, 38, 93-113. https://doi.org/10.1177/1321103X16642632

Yunus, F. W., Bissett, M., Penkala, S., Romli, M. H., \& Liu, K. P. Y. (2021). Self-Regulated Learning versus Activity-Based Intervention to Reduce Challenging Behaviors and Enhance School-Related Function for Children with Autism Spectrum Disorders: A Randomized Controlled Trial. Research in Developmental Disabilities, 114, Article ID: 
103986. https://doi.org/10.1016/j.ridd.2021.103986

Yunus, F. W., Bissett, M., Stefania Penkala, S., Romli, M. H., \& Liu, K. P. Y. (2020). Advisory Panel Review on the Feasibility of Three Intervention Programmes for Children with Autism Spectrum Disorder. Malaysian Journal of Medicine and Health Sciences, $16,43-51$. 